\title{
Discovery of small molecule inhibitors against the NS3/4A serine protease of Hepatitis $C$ virus genotype 3 via high- throughput virtual screening and in vitro evaluations
}

\author{
Sakhor, W. ${ }^{1}$, Teoh, T.C. ${ }^{2}$, Yusof, R. ${ }^{1}$, Lim, S.K. ${ }^{3}$ and Razif, M.F.M. ${ }^{{ }^{*}}$ \\ ${ }^{1}$ Department of Molecular Medicine, Faculty of Medicine, University of Malaya, 50603 Kuala Lumpur, Malaysia \\ ${ }^{2}$ Institute of Biological Sciences, Faculty of Science, University of Malaya, 50603 Kuala Lumpur, Malaysia \\ ${ }^{3}$ Department of Pharmaceutical Chemistry, Faculty of Pharmacy, University of Malaya, 50603 Kuala Lumpur, \\ Malaysia \\ *Corresponding author e-mail: fazril.razif@um.edu.my \\ Received 17 February 2020; received in revised form 5 May 2020; accepted 6 May 2020
}

\begin{abstract}
The hepatitis $\mathrm{C}$ virus (HCV) consists of eight genotypes and 90 subtypes, with genotype (GT) 3 being the second most common globally and is linked to higher incidences of steatosis and rapid development of fibrosis and cirrhosis. The NS3/4A serine protease, a heterodimer complex of two HCV non-structural proteins, is an effective target for pharmaceutical intervention due to its essential roles in processing HCV polyproteins and inhibiting innate immunity. This study combines structure-based virtual screening (SBVS) of predefined compound libraries, pharmacokinetic prediction (ADME/T) and in vitro evaluation to identify potential low molecular weight $(<500$ Dalton) inhibitors of the NS3/4A serine protease (GT3). In silico screening of ZINC and PubChem libraries yielded five selected compounds as potential candidates. Dose-dependent inhibition of the NS3/4A serine protease and HCV replication in HuH-7.5 cells revealed that compound A (PubChem ID No. 16672637) exhibited inhibition towards HCV GT3 with an $\mathrm{IC}_{50}$ of $106.7 \mu \mathrm{M}$ and $\mathrm{EC}_{50}$ of $25.8 \mu \mathrm{M}$, respectively. Thus, compound A may be developed as a potent, low molecular weight drug against the HCV NS3/4A serine protease of GT3.
\end{abstract}

\section{INTRODUCTION}

Hepatitis $\mathrm{C}$ is a global health concern that affects $\sim 177.5$ million people, representing nearly $2.5 \%$ of the world population (Petruziello et al., 2016), and is one of the main causes of death and morbidity. The disease is caused by the hepatitis $\mathrm{C}$ virus (HCV), a blood borne virus that was first discovered in 1989 (Choo et al., 1989). HCV is classified under the genus Hepacivirus and is a member of the Flaviviridae family (Simmonds et al., 2017). Early stage diagnosis of the disease is difficult because acute infections are frequently asymptomatic. About 75-85\% of those with acute HCV infection will eventually develop a chronic infection, leading to fibrosis, cirrhosis and hepatocellular carcinoma (Pinzani et al., 2005; Hajarizadeh et al., 2013). HCV displays a high degree of genetic heterogeneity due to the error-prone nature of RNA-dependent RNA polymerase. At present, there are eight confirmed genotypes (GT) and 90 subtypes of HCV (Smith et al., 2019). Amongst all genotypes, GT3 infection is relatively difficult to treat, especially in patients with prior $\mathrm{HCV}$ treatment failure or cirrhosis. GT3 infection is associated with higher incidences of steatosis (Hwang \& Lee, 2011; Roingeard, 2013), rapid development of fibrosis and cirrhosis, and higher rates of hepatocellular carcinoma (Kanwal et al., 2014; Chan et al., 2017).

The HCV RNA genome encodes for a long polyprotein precursor which consists of four structural proteins (C, E1, E2 and p7) 
and six non-structural proteins (NS2, NS3, NS4A, NS4B, NS5A and NS5B). This large polyprotein is cleaved into 10 individual proteins by the action of both cellular and viral proteases (Kim et al., 1996). The NS3/ $4 \mathrm{~A}$ serine protease cleaves at four junctions, between NS3/NS4A (self-cleavage), NS4A/NS4B, NS4B/NS5A and NS5A/NS5B (Baetenschlager \& Lohmann, 2000) which is critical to the HCV replication system as viral replication can only begin after all individual proteins have been cleaved. The $\mathrm{NS} 3 / 4 \mathrm{~A}$ serine protease is also involved in the inhibition of innate immunity. Cleavage of the TIR-domain-containing adapterinducing IFN- $\beta$ and mitochondrial antiviral signalling protein prevents the activation of interferon type I genes and IFN-stimulated genes (Dustin \& Rice, 2007) while cleavage of T-cell protein tyrosine phosphatase interferes with the growth signaling/Akt pathway Brenndörfer et al., 2009). Its significant roles in viral replication and pathogenesis of HCV make the NS3/4A serine protease a fascinating target for therapeutic development.

Unlike both hepatitis A (HAV) and hepatitis B (HBV) virus, there are currently no vaccines against HCV. In May 2011, the United States Food and Drug Administration (U.S. FDA) approved the first generation of direct-acting antivirals (DAAs), Boceprevir (Chen \& Njoroge, 2010) and Telaprevir (Kwong et al., 2011), to treat HCV. Since then, numerous highly potent DAAs targeting the NS3/4A protease (Rosenquist et al., 2014; Ng et al., 2018), NS5A (Belema et al., 2014; Yu et $a l ., 2018$ ) and NS5B polymerase (Sofia, 2016; ElKassas et al., 2017) have been developed. Yet, some are only effective against certain genotypes. At present, first-generation DAAs are no longer recommended due to their adverse side effects and reduced efficacy (World Health Organization, 2017). Earlier standard of care for GT3-infected patients was achieved via the combination therapy of Sofosbuvir-Ribavirin; however, the sustained virologic response is low compared to the other genotypes (Jacobson et al., 2013; Lawitz et al., 2013). Current treatment options recommended for GT3 infections, which consists of a combination of dual and triple DAAs (AASLD-IDSA, 2018; Pawlotsky et al., 2018), have shown to provide greater efficacy, even in cirrhotic and treatmentexperienced patients (Foster et al., 2015; Wyles et al., 2018). However, (i) the high costs associated with these newer therapies, (ii) the association of GT3 with greater liver complications, and (iii) the presence of resistance-associated substitutions that affect tolerances to DAAs (Vermehren \& Sarrazin, 2012; Poveda et al., 2014; Lontok et al., 2015; Raj et al., 2017) emphasizes the need for continuous DAA development.

Numerous computer-aided approaches have been employed to discover new potent HCV inhibitors (Li et al., 2013; Kumar et al. 2014; Basetto et al., 2016; Ganesan \& Barakat, 2017) by combing through large virtual compound databases, followed by in vitro and in vivo evaluations. Therefore, this study employs structure-based virtual screening (SBVS) of current predefined compound libraries to identify potential potent, low molecular weight inhibitors targeting the NS3/4A serine protease of wild type HCV GT3, followed by in vitro investigations into the potency of the selected compounds.

\section{MATERIALS AND METHODS}

\section{Protein 3D structure modeling of GT3 NS3/4A serine protease}

HCV GT3 NS3/4A serine protease protein $3 \mathrm{D}$ structure is needed for high-throughput virtual screening. Therefore, homology modeling by YASARA (www.yasara.org) was used to construct a model of the NS3/4A serine protease based on CASP-approved protocol. The HCV GT3 protein sequence was retrieved from UniProt (Id: I1Y879) and the templates for homology modeling were identified from the PDB database (PDB ID: 4A1X, 308B, 4A92, 3M5M and 4I33). The models generated underwent structure validation based on Z- scores calculated from molecular dynamic force field energies. The stereochemical qualities of selected model of NS3/4A serine protease (4A1X-B02) was further validated by generating Ramachandran plot using Procheck: 
http://servicesn.mbi.ucla.edu/PROCHECK/ (Laskowski et al., 1993). Compatibility of the $3 \mathrm{D}$ atomic models to the NS3/4A amino acid sequence was confirmed via Verify3D: http://servicesn.mbi.ucla.edu/Verify3D/ (Liithy et al., 1992). The verified homology model was used as the template for virtual screening.

\section{Virtual screening}

Virtual screening was performed using Mobyle@RPBS and Idock webservers which provides a large database of compounds from PubChem and ZINC (Irwin et al., 2012) respectively. Mobyle@RPBS provides virtual screening services under the MTiOpenScreen program that operates with Autodock Vina and Vina empirical scoring function (Alland et al., 2005; Néron et al., 2009). Idock is a tool for structure-based virtual screening for flexible ligand docking that is motivated from Autodock Vina ( $\mathrm{Li}$ et al., 2012). MTiOpenScreen (Labbé et al., 2015) by Mobyle@RPBS provides predefined libraries curated from PubChem: i) 99288 diverse chemical compound collections and ii) 51232 focused chemical compound collections that target protein-protein interactions. In addition, there were a total of 23129083 compounds from ZINC available via Idock. All compounds were filtered according to conditions outlined by Lipinski's rule of 5 to obtain a lead-like compound.: no more than 5 hydrogen bond donors, no more than 10 hydrogen bond acceptors, molecular weight less than 500 Daltons and log P not greater than 5 (Lipinski et al., 1997; 2001). Overall, there were 90000 compounds screened from the two webservers. Virtual screening with Mobyle@RPBS and Idock was performed by targeting the search space calculated from protein residues on the active site; particularly the catalytic triad (His57, Asp81, and Ser139) of the GT3 NS3/4A serine protease.

\section{ADME/T prediction}

Absorption, distribution, metabolism, excretion and toxicity (ADME/T) properties of the 300 selected compounds were predicted using Discovery Studio 4.5. A total of 217 compounds were removed from further analysis because they possessed no interactions with the wild type GT3 NS3/4A serine protease catalytic triad (His57, Asp81, and Ser139) and/or having unfavorable ADME/T properties. Evaluation of the toxicity potential for the remaining compounds were conducted based on the TOxicity Prediction by Komputer Assisted Technology (TOPKAT; Accelrys).

\section{Redocking}

83 shortlisted compounds were redocked locally using Autodock Vina (Trott \& Olson, 2010) to observe its reproducibility. Simeprevir, a DAA used for the treatment of HCV GT1, was used as the standard compound in virtual screening and redocking. The crystal structure was obtained from RCSB Protein Data Bank (PDB) database: 3KEE and extracted out from protein-ligand complex with Discovery Studio 4.5. The NS3/ $4 \mathrm{~A}$ protein and selected ligands structure were prepared and saved in pdbqt format using AutodockTools 1.5.6 software. Configuration file named "conf.txt" were prepared; the input includes the receptor and ligand file in pdbqt format, search space area to be docked by ligands in $\mathrm{x}, \mathrm{y}$, $\mathrm{z}$ dimensions; $22 \AA \mathrm{x} 20 \AA \mathrm{x} 20 \AA$ with $\mathrm{x}, \mathrm{y}$ and $\mathrm{z}$ coordinates of the center 57.002, 74.518, -48.664 respectively. The exhaustiveness was set at 100 and the output file was named as "out.pdbqt". Docking was run following manual in http://vina.scripps. edu/tutorial.html

\section{Redocking analysis}

The outputs of docking by Autodock Vina were analysed by PyMOL (The PyMOL Molecular Graphics System, Version 1.3 Schrodinger, LLC). 2D interaction diagrams were examined via Discovery Studio 4.5 (Dassault Systèmes BIOVIA). Each compound was ranked based on its free binding energies as compared to Simeprevir, binding interactions with residue in the GT3 NS3/4A catalytic triad (His57, Asp81, Ser 139) and the Oxyanion hole (Gly137). Docking simulations had produced nine binding conformations by default for each compound; these binding conformations were scored based on their binding frequency to the 
catalytic triad. The output lists 18 compounds that presented interactions with any of the three amino acids in the catalytic triad with binding conformations score $\geq 4$ (Supplementary Material; Table S1). Five compounds named A, B, C, D and E (Table 2) were selected and purchased from Asinex, USA (A), ChemBridge, USA (B, E), Enamine, USA (C) and KeyOrganics, UK (D); with $\geq 90 \%$ purity to investigate their inhibitory potential against the NS3/4A serine protease of GT3 in vitro.

\section{Recombinant GT3 NS3/4A protein expression and purification}

A fusion gene containing a NS4A fragment linked to a NS3 serine protease domain by a GSGS-linker was synthesized in a pUC57 plasmid (Nanogene Solutions) with flanking BamHI and HindIII restriction sites for cloning. The NS4A-GSGS-NS3 gene was subcloned into the pQE30 plasmid (Qiagen) and expressed as a fusion with a hexahistidine tag in Escherichia coli Rosetta cells. Recombinant protein was expressed by the addition of $0.5 \mathrm{mM}$ IPTG followed by $5 \mathrm{~h}$ incubation at room temperature. Cells were lysed by sonication in $50 \mathrm{mM}$ Hepes, $300 \mathrm{mM} \mathrm{NaCl}$, lysozyme, 10\% glycerol, ( $\mathrm{pH}$ 7.8). Lysates were centrifuged at $8800 \mathrm{x} \mathrm{g}$ for $40 \mathrm{~min}$ at $4{ }^{\circ} \mathrm{C}$ to obtain cell-free supernatant. Soluble protein fractions were incubated with pre-equilibrated $\mathrm{Ni}^{2+}$-NTA (Gold Bio) resin for $2 \mathrm{~h}$ at $4^{\circ} \mathrm{C}$ on a rocking platform. The $\mathrm{Ni}^{2+}$-NTA resin was washed twice with $50 \mathrm{mM}$ Hepes, $300 \mathrm{mM} \mathrm{NaCl}, 30 \mathrm{mM}$ imidazole $(\mathrm{pH}$ 7.8) and the NS3/4A protein was eluted with $50 \mathrm{mM}$ Hepes, $300 \mathrm{mM} \mathrm{NaCl}$, $150 \mathrm{mM}$ imidazole ( $\mathrm{pH}$ 7.8). Eluted protein was determined by sodium dodecyl sulphatepolyacrylamide gel electrophoresis (SDSPAGE) and verified via Western blot analysis. The NS3/4A protein was stored in 50\% glycerol at $-80^{\circ} \mathrm{C}$.

\section{Protease activity assay}

All five compounds were dissolved in $100 \%$ DMSO $(10 \mathrm{mM})$ and diluted with assay buffer (50mM Hepes, 300mM NaCl, 20\% glycerol, 10mM DTT). Varying concentrations (triplicates) of each compound were incubated with 20nM of purified GT3 NS3/4A protein in a black 96 -well plate for $10 \mathrm{~min}$ at $30^{\circ} \mathrm{C}$ with shaking. The reactions were initiated by addition of $5 \mu \mathrm{M}$ substrate (AcDE-D(EDANS)-EE-Abu- $\psi$-[COO]-AS-K (DABCYL)-NH2). Fluorescence signal was monitored for $30 \mathrm{~min}$ at $340 / 490 \mathrm{~nm}$ using the Infinite 200 microplate reader (Tecan). GraphPad Prism (GraphPad Software, Inc.) was used to determine the $\mathrm{IC}_{50}$ value of each compound.

\section{Cell culture}

HuH-7.5 cells were cultured in Dulbecco's Modified Eagle's medium (DMEM) supplemented with $10 \%$ fetal bovine serum (Gibco). Transfected HuH-7.5 cells stably expressing S52/SG-Feo (SHI) were maintained in DMEM medium with $10 \%$ fetal bovine serum and $250 \mu \mathrm{g} / \mathrm{ml} \mathrm{G418}$. Cells were incubated at $37^{\circ} \mathrm{C}$ in humidified atmosphere with $5 \%$ $\mathrm{CO}_{2}$. Huh-7.5 cells were confirmed to be absent of mycoplasma contamination.

\section{Cytotoxicity assay}

Toxicity of each compound against Huh-7.5 cells was measured using Cell titer $96^{\mathrm{R}}$ Aqueous One Solution Cell Proliferation Assay (Promega). $1 \times 10^{4}$ cells were seeded per well in a 96-well plate and incubated at $37^{\circ} \mathrm{C}$ in humidified atmosphere with $5 \%$ $\mathrm{CO}_{2}$ overnight. Increasing concentrations of each compound $(0 \mu \mathrm{M}, 6.25 \mu \mathrm{M}, 12.5 \mu \mathrm{M}$, $25 \mu \mathrm{M}, 50 \mu \mathrm{M}, 100 \mu \mathrm{M}, 200 \mu \mathrm{M})$ was added to triplicate wells and incubated for $72 \mathrm{~h}$. Cell viability was measured using Epoch Microplate Spectrophotometer (Biotek) at 490nm.

\section{In vitro transcription and transfection}

Neomycin-selectable subgenomic replicon of GT3 with firefly luciferase reporter gene in its construct, S52/SG-Feo (SHI) plasmid was transformed into $E$. coli DH5 $\alpha$ strain. The plasmid DNA was isolated and used as template to synthesize RNA via in vitro transcription using RiboMAX ${ }^{\mathrm{TM}}$ Large Scale RNA Production System-T7 (Promega). Prior to transcription, the plasmid was linearized with FastDigest XbaI (Thermo Fisher) and purified with PCR Purification Mini kit (Favorgen) according to manufacturer's instructions. RNA concentration and purity 
were determined using Thermo Scientific NanoDrop ${ }^{\mathrm{TM}}$ 2000/2000c Spectrophotometer. S52/SG-Feo (SHI) RNA was transfected into HuH-7.5 cells using Lipofectamine 3000 reagent (Thermo Fisher). Selection of colonies was achieved with $600 \mu \mathrm{g} / \mathrm{ml}$ G418 for two weeks. Subsequently, cells were maintained with $250 \mu \mathrm{g} / \mathrm{ml} \mathrm{G} 418$.

\section{Luciferase-based replicon assay}

HuH-7.5 cells stably expressing S52/SG-Feo (SHI) were seeded at $1 \times 10^{4}$ cells per well in a white 96-well plate overnight. Compounds $\mathrm{A}$ and $\mathrm{D}$ were diluted in culture medium at varying concentrations and maintained in $1 \%$ DMSO. (Compound A: $5 \mu \mathrm{M}, 10 \mu \mathrm{M}, 15 \mu \mathrm{M}$, $20 \mu \mathrm{M}, 30 \mu \mathrm{M}, 40 \mu \mathrm{M}$; Compound D: $10 \mu \mathrm{M}$, $50 \mu \mathrm{M}, 100 \mu \mathrm{M}, 150 \mu \mathrm{M}, 200 \mu \mathrm{M})$. After $72 \mathrm{~h}$, viral RNA replication was evaluated using ONE-Glo ${ }^{\mathrm{TM}}$ EX Luciferase Assay System (Promega). Measurements were taken using the Infinite 200 microplate reader (Tecan).

\section{Statistical analysis}

Assays were conducted in triplicates in the presence of a vehicle control. GraphPad Prism software (GraphPad Software, Inc.) was used to determine the $\mathrm{IC}_{50}$ in the protease activity assay, $\mathrm{CC}_{50}$ values in the cytotoxicity assay and $\mathrm{EC}_{50}$ value in the luciferase assay as well as determining means, standard deviations and standard error. The statistical analysis of one-way ANOVA was conducted, results obtain has significant difference at $\mathrm{P}<0.05$.

\section{RESULTS}

The 3D structure of wild type GT3 NS3/4A serine protease was predicted via homology modeling; Figure 1a and Figure 1b. A position-specific scoring matrix (PSSM) was built by running PSI-BLAST of NS3/4A target sequences against UniProt. Potential templates were identified in the PDB database based on the PSSM profile. The templates were ranked based on alignment scores and structural quality. Out of the 46 hits found, five templates with the highest scores were selected namely PDB: 4A1X, 308B, 4A92, 3M5M and 4I33. These 5 templates are from HCV G1a and G1b. Nine protein models were generated from the five selected templates. Loops were modeled and the side chains built were optimized and finetuned. Combined steepest descent and simulated annealing minimization was applied to the modeled parts. All models were validated based on Z-scores of molecular dynamics force fields energies (Table 1). The model with the best overall quality Z-score, 4A1X-B02 was selected for further study.

The quality of the 4A1X-B02 model was further verified by generating a Ramachandran plot to assess the stereochemical qualities of the protein; Figure 1c. Based on the plot, this model was considered to possess acceptable stereochemical qualities as $92.5 \%$ of the residues were located in the most favored regions, with no residues detected in the disallowed regions. The structure was also confirmed via Verify3D to assess the compatibility of the $3 \mathrm{D}$ atomic model to its amino acid sequence. The results revealed that $90.31 \%$ of the residues had an average 3D-1D score of $\geq 0.2$ in the $3 \mathrm{D} / 1 \mathrm{D}$ profile.

A multi-step approach was employed in search for potential small molecule inhibitors against the NS3/4A serine protease of HCV GT3; Figure 1d. Two large databases of compounds currently accessible via ZINC and PubChem were explored. SBVS of compounds was accomplished using Mobyle@RPBS and Idock webservers, followed by prediction into their ADME/T properties and redocking via Autodock Vina. Following redocking, 18 compounds were shortlisted. Potential compounds were selected with conditions as follows: (i) molecular weight $\leq 500$ Dalton, (ii) comparable binding affinity as the standard, Simeprevir (iii) interactions with at least one residue in the catalytic triad, (iv) binding conformations score $\geq 4(\mathrm{v})$ favorable ADME/T properties. Five purchasable compounds were selected for further evaluation in vitro. The IUPAC name, identity number, binding affinities, conformation scores and molecular weight of these five compounds are summarized in Table 2. The 5 compounds are labeled as compound A, $\mathrm{B}, \mathrm{C}, \mathrm{D}$ and $\mathrm{E}$. 
a)

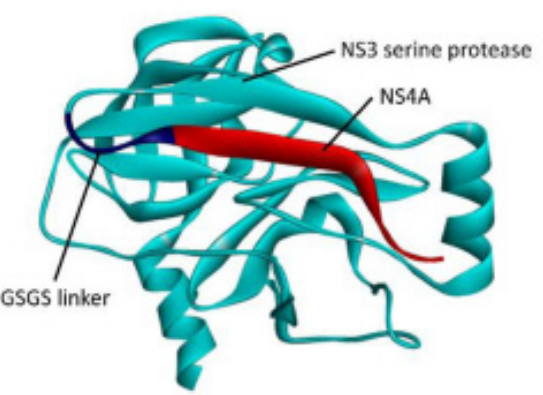

c)

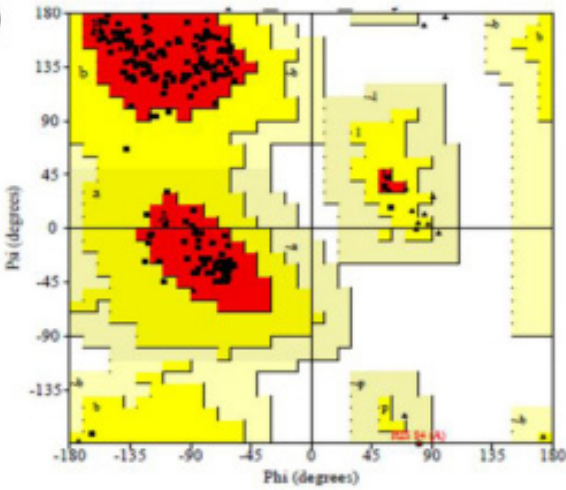

b)

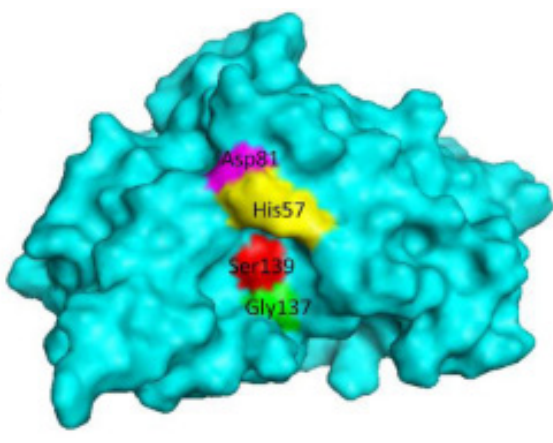

d)

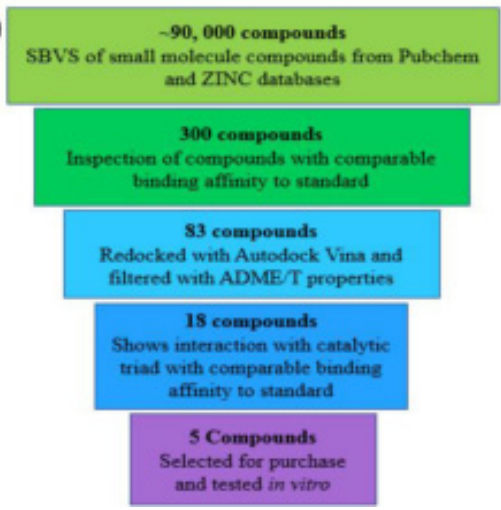

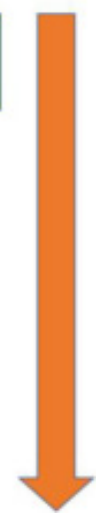

Figure 1. 3D structural modelling of the HCV (GT3) NS3/4A serine protease and inhibitor screening approach.

(a) Structural motif of the NS3/4A serine protease in solid ribbon (Cyan: NS3 serine protease; Blue: GSGS linker; Red: NS4A cofactor). (b) Surface display of the NS3/4A serine protease. The binding pocket of its active site is highlighted in yellow (His57), red (Ser139) and magenta (Asp81). The oxyanion hole is highlighted in green (Gly137; Cyan: NS3 serine protease). (c) Ramachandran plot of model 4A1X-B02 generated from PROCHECK. Red represents the most favoured regions; yellow represents additional allowed regions; cream represents generously allowed regions; white represents disallowed regions. A good quality model is expected to possess $\geq 90 \%$ amino acid residues in the most favoured regions. In this model, $92.5 \%$ of residues are located within the most favoured regions. (d) Multi-step approach employed in silico in search of potential small molecule inhibitors against the NS3/4A serine protease.

Table 1. Model ranking of the initial homology models generated from YASARA.

The models are ranked based on Z- scores of structural validations calculated from molecular dynamics force field energies. The model with the best overall quality Z-score; 4A1X-B02 was accepted as the final model.

\begin{tabular}{ccccccc}
\hline Rank & Model ID & $\begin{array}{c}\text { Dihedral } \\
\text { Z-score }\end{array}$ & $\begin{array}{c}\text { 1D } \\
\text { Z-score }\end{array}$ & $\begin{array}{c}\text { 3D } \\
\text { Z-score }\end{array}$ & $\begin{array}{c}\text { Overall quality } \\
\text { Z-score }\end{array}$ & Comment \\
\hline $\mathbf{1}$ & 4A1X-B02 & $\mathbf{2 . 1 3 7}$ & $\mathbf{- 0 . 7 1 4}$ & $\mathbf{- 1 . 2 8 1}$ & $\mathbf{- 0 . 5 6 4}$ & Good \\
2 & 3O8B-A02 & 1.821 & -0.745 & -1.359 & -0.658 & Good \\
3 & 3O8B-A01 & 1.770 & -0.830 & -1.345 & -0.692 & Good \\
4 & 4A1X-B01 & 1.849 & -0.972 & -1.470 & -0.795 & Good \\
5 & 4A1X-B03 & 1.652 & -1.019 & -1.520 & -0.865 & Good \\
6 & 3M5M-B & 1.997 & -1.145 & -1.610 & -0.906 & Good \\
7 & 4I33-A & 1.465 & -1.516 & -1.230 & -0.951 & Good \\
8 & 4A92- 02 & 1.364 & -1.060 & -1.862 & -1.081 & Satisfactory \\
9 & 4A92- 01 & 1.073 & -1.388 & -2.124 & -1.373 & Satisfactory \\
\hline
\end{tabular}


From docking simulations on Autodock Vina, compound A possessed the same binding affinity $(-7.8 \mathrm{Kcal} / \mathrm{mol})$ as Simeprevir. The other four compounds exhibited comparable binding affinities (Table 2). These simulations also revealed that all five compounds successfully bound to the shallow groove within the active site of the GT3 NS3/4A serine protease. Binding conformations of Compound A and D scored $8 / 9$ and $9 / 9$, indicating that most of the conformations successfully docked inside the active site and interacted with key residues of the catalytic triad, namely Ser139 and His57 via hydrogen bonding and van der Waals interactions, respectively. Both compounds also possessed interactions with Gly137 of the oxyanion hole, and residues of the hydrophobic pockets. The structure and binding dynamics of each compound are shown in Figure 2.
All selected compounds obey Lipinski's rule of 5; however the selected standard, Simeprevir has two violations (i) molecular weight higher than 500 Dalton, and (ii) possess more than 10 hydrogen bond acceptors. ADME/T screening via Discovery Studio 4.5 predicted that only compound $\mathrm{B}$ has good solubility whereas the other compounds, including Simeprevir, have poor solubility. The oral bioavailability and intestinal absorption of all five compounds are predicted to be very high. Only compound $\mathrm{D}$ is predicted to inhibit the function of cytochrome P450 2D6. Evaluation of their toxicity potential using TOPKAT predicted that all compounds, including Simeprevir, are non-mutagenic and non-toxic.

Purified GT3 NS3/4A serine protease with a molecular mass of $\sim 23 \mathrm{Kda}$ (Du et al., 2002) was obtained via overexpression in $E$. coli Rosetta and confirmed by SDS-PAGE and

Table 2. IUPAC name, binding affinity and ADME/T properties of five shortlisted compounds, with Simeprevir as a standard

\begin{tabular}{lcccc}
\hline & & Binding \\
Compound Identifier/IUPAC Name & Identity & $\begin{array}{c}\text { Affinity } \\
(\text { Kcal/mol })\end{array}$ & $\begin{array}{c}\text { Conformation } \\
\text { Score }^{\mathrm{b}}\end{array}$ & $\begin{array}{c}\text { Molecular } \\
\text { Weight } \\
\text { (Dalton) }\end{array}$ \\
\hline
\end{tabular}

$\mathbf{A}$

[(3S)-1-[5-(1,3-benzodioxol-5-yl)1,2-oxazole-3-carbonyl] piperidin3-yl] -(2-fluorophenyl) methanone

Pubchem

$\begin{array}{lll}16672637 & -7.8 & 8 / 9\end{array}$

422.41

\section{B}

(3aR,4R)-3-cyclobutyl-4-(2-quinolyl)

-3a,4,5,7-tetrahydropyrazolo [3,4-b] pyridin -6-one

\section{C}

(4S)-2-oxo-N-[6-(trifluoromethyl)-2 -pyridyl]-3,4-dihydro-1H-quinoline4-carboxamide

ZINC
65463613

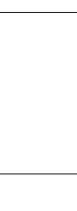

$\begin{array}{cccc}\text { ZINC } & -7.6 & 7 / 9 & 335.28 \\ 75126755 & & \end{array}$

\begin{tabular}{|c|c|c|c|c|}
\hline $\begin{array}{l}\text { D } \\
\text { 2-[2-[2-(4-fluorophenyl)-1,3-thiazol- } \\
\text { 4-yl] ethyl] isoindole-1,3-dione }\end{array}$ & $\begin{array}{c}\text { Pubchem } \\
1473490\end{array}$ & -7.4 & $9 / 9$ & 352.38 \\
\hline $\begin{array}{l}\mathbf{E} \\
{[(2 \mathrm{R})-2 \text {-hydroxyspiro[indane-1,4'- }} \\
\text { piperidine]-1'-yl]-[3-(m-tolyl)-1H- } \\
\text { pyrazol-4-yl] methanone }\end{array}$ & $\begin{array}{c}\text { ZINC } \\
72124233\end{array}$ & -7.2 & $4 / 9$ & 387.47 \\
\hline Simeprevir & & -7.8 & $8 / 9$ & 749.94 \\
\hline
\end{tabular}

a Binding Affinity of best conformations predicted by Autodock Vina (Kcal/mol).

${ }^{b}$ Number of conformations that interact with amino acid residue of catalytic triad. 


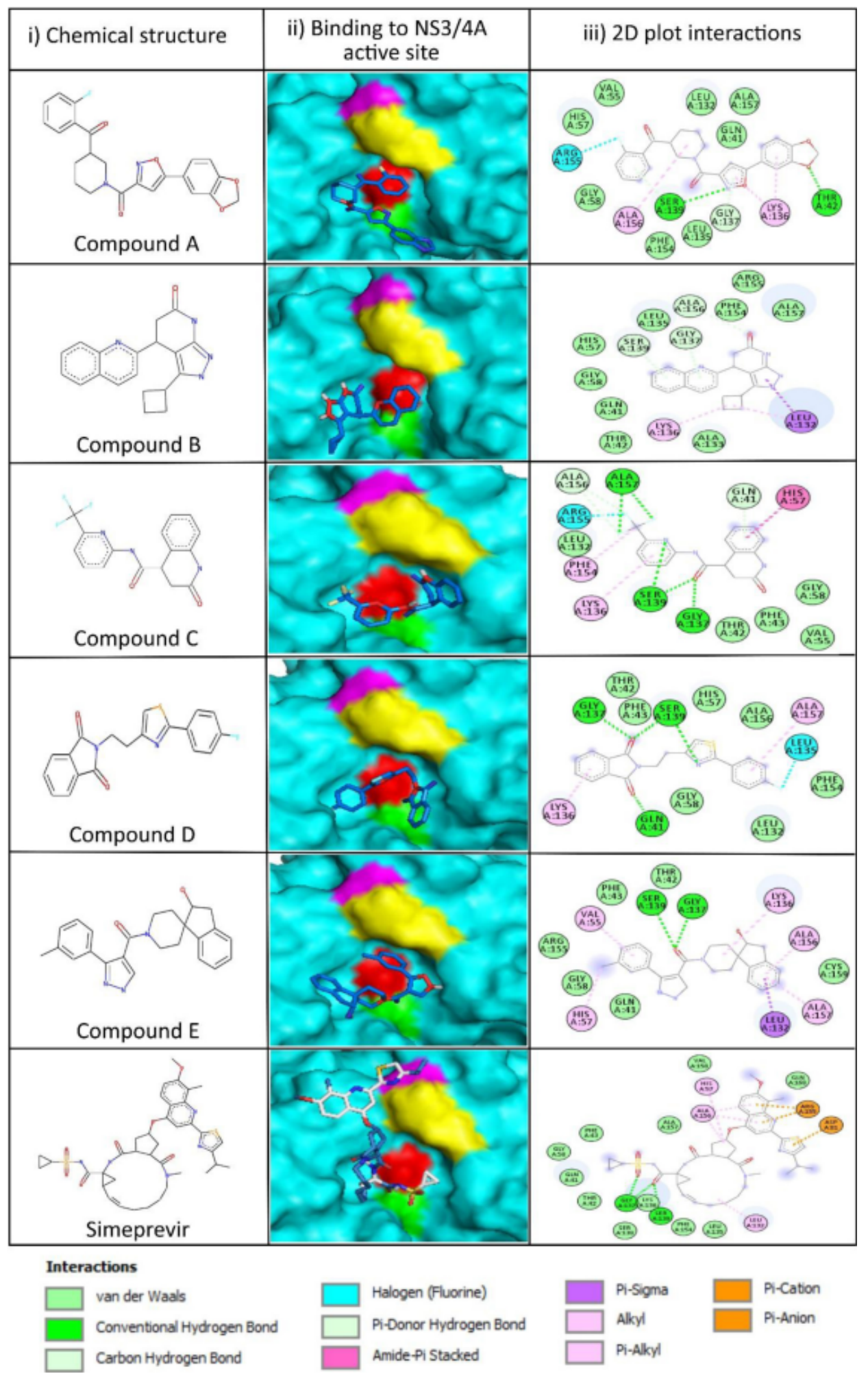

Figure 2. Chemical structures and binding dynamics of compound A, B, C, D, E and Simeprevir. (i) Chemical structures of compound A, B, C, D, E and Simeprevir. (ii) Binding of each compound to the NS3/4A active site; Red: Ser139; Green: Gly137; Yellow: His57; Magenta: Asp81; Cyan: NS3/4A. (iii) 2D plot showing interactions of each compound with amino acids in the vicinity of the NS3/4A active site. 
Western blot (Supplementary Material; Figure S1). A FRET-based assay was employed to evaluate the inhibitory activities of each compound against the NS3/4A serine protease. Initial screenings of all compounds at $100 \mu \mathrm{M}$ demonstrated that compound A (40.8\%) and D (48.9\%) exhibited the greatest inhibition against the NS3/4A serine protease (Supplementary Material; Figure. S2). On the contrary, compound B appears to enhance protease activity by $24.8 \%$. Both compound $\mathrm{A}$ and D were subsequently selected for further analysis. Results confirmed that both compounds A and D exhibited dosedependent inhibition of the GT3 NS3/4A serine protease, each possessing an $\mathrm{IC}_{50}$ of $106.7 \mu \mathrm{M}$ and $86 \mu \mathrm{M}$, respectively; Figure 3a and $3 \mathrm{~b}$.

Next, cell-based assays were performed to determine the cytotoxicity and inhibitory potential of both compounds on $\mathrm{HCV}$ replication. The 50\% cytotoxicity concentration $\left(\mathrm{CC}_{50}\right)$ of compounds $\mathrm{A}$ and $\mathrm{D}$, as determined $72 \mathrm{~h}$ after exposure in Huh-7.5 cells, is $139.5 \mu \mathrm{M}$ and $>200 \mu \mathrm{M}$, respectively; Figure $3 c$ and $3 d$. Following this, Huh-7.5 cells stably transfected with S52/SG-Feo (SHI), a bicistronic subgenomic replicon for $\mathrm{HCV}$ GT3a with firefly luciferase reporter gene in its construct, was used to determine viral RNA levels in cells post-treatment (Saeed et al., 2012). Increasing concentrations of compounds A and D were added to the transfected cells and incubated for $72 \mathrm{~h}$. Compound A successfully inhibited $81 \%$ of $\mathrm{HCV}$ replication at $40 \mu \mathrm{M}$, with an $50 \%$ effective concentration $\left(\mathrm{EC}_{50}\right)$ of $25.8 \mu \mathrm{M}$; Figure 3e. Compound D was only able to inhibit $45.6 \%$ of HCV replication at $200 \mu \mathrm{M}$; Figure $3 \mathrm{f}$. The $\mathrm{EC}_{50}$ of compound D could not be determined due to its limited solubility. Overall, compound A was able to inhibit HCV replication in Huh-7.5-S52/SG-Feo (SHI) with a selectivity index $\left(\mathrm{CC}_{50} / \mathrm{EC}_{50}\right)$ of 5.40 .

\section{DISCUSSIONS}

This study combines in silico and in vitro methods in search for potential small molecule inhibitor candidates for wild type HCV GT3 NS3/4A serine protease. In silico virtual screening of compounds require protein 3D structure of GT3 NS3/4A. There are currently 123 crystal structures of HCV NS3/4 serine proteases deposited in the Protein Data Bank (PDB). However, only one, a GT1a3a chimera created by substituting three active site polymorphisms (R123T, D168Q and I132L) into GT1a NS3/4A, has been determined for GT3. No other structures of non-GT1 NS3/4A have been determined. Among the reasons is difficulty in performing crystallography due to complications in large-scale expression and purification (Soumana et al., 2016). In our study, homology modeling was able to predict the 3D structure of HCV GT3 NS3/4A serine protease, based on the actual GT3 amino acid sequence, via a protocol that adopts critical assessment of structure prediction (CASP). Generating Ramachandran plots and Verify 3D further aided in assessing the quality of the 3D structures (Lüthy et al., 1992; Carugo et al., 2013). Based on the plot displaying dihedral angles psi, $\psi$ against phi, $\varphi$ of amino acid residues, the $3 \mathrm{D}$ protein structure of model 4A1X-B02 possessed adequate stereochemical qualities with $>90 \%$ residues located in the most favored regions and no residues detected in the disallowed regions. Residues that deviate far from the allowed regions imply there are some error with the structure (Carugo \& Djinovic-Carugo, 2013). Nonetheless, there are studies that report estimation of $0.4 \%$ residues located in the disallowed regions (Pal \& Chakrabarti, 2002). Our Verify 3D result showed high-profile scores of compatibilities between the GT3 NS3/4A serine protease 3D structure and its amino acid sequence. At least $80 \%$ of the amino acids scoring $>0.2$ in the $3 \mathrm{D} / 1 \mathrm{D}$ profile is required for an estimation of accurate protein structure matched to its amino acid sequence.

The catalytic site of the GT3 NS3/4A serine protease was chosen as a target in virtual screening to inhibit viral replication. The catalytic site comprises of three amino acid residues, His57, Asp81, and Ser139, also known as the catalytic triad; Figure 1(b) (Kim et al., 1996; Love et al., 1996; Lin, 2006). They function by performing catalytic acid-base reactions on its target peptides (Hedstrom, 


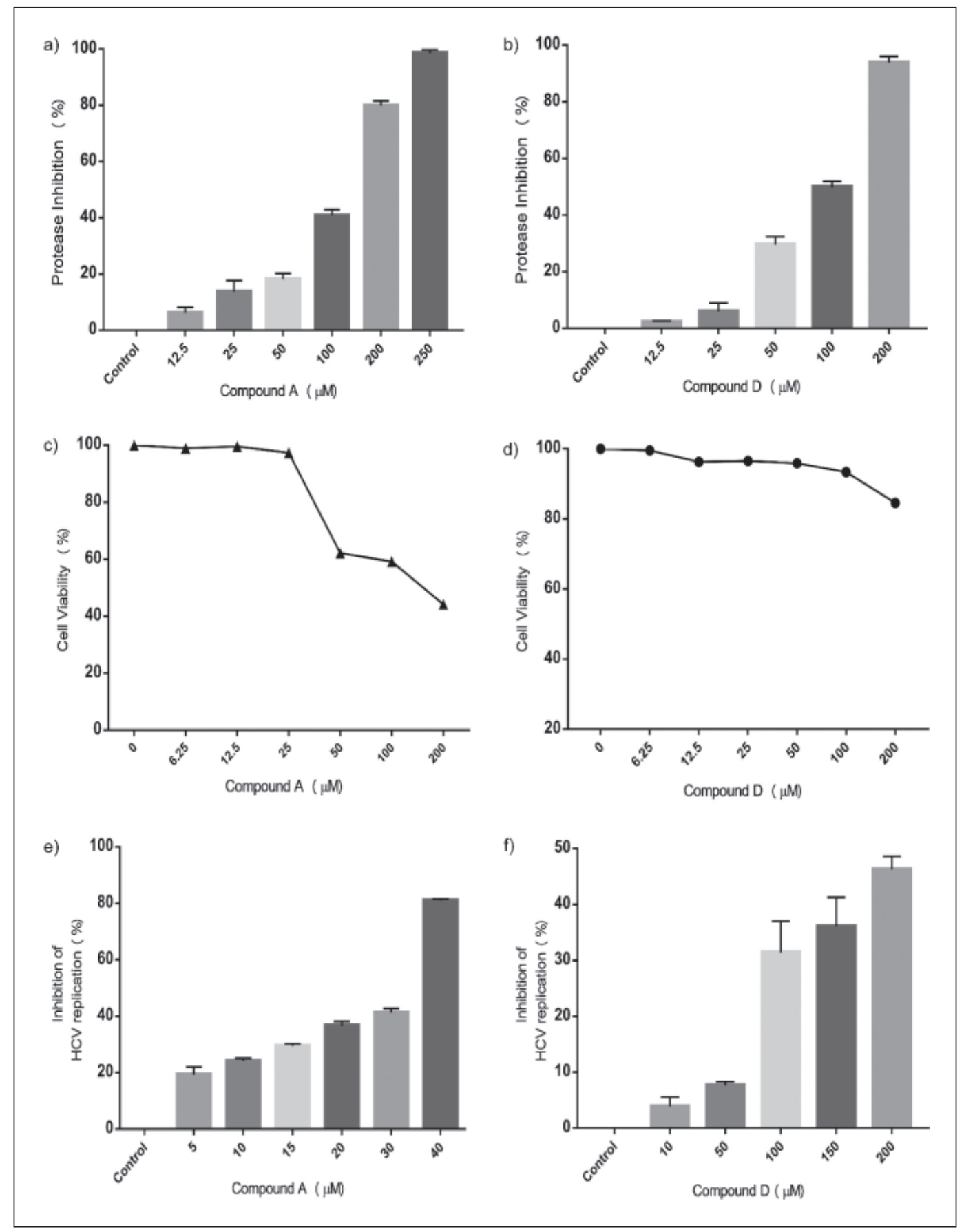

Figure 3. Inhibitory potential of compounds A and D via in vitro assays.

(a) Dose-dependent inhibition (\%) of NS3/4A serine protease by compound A. (b) Dose-dependent inhibition (\%) of NS3/4A serine protease by compound D. (c) Cell viability (\%) of HuH-7.5 cells upon treatment with compound A. (d) Cell viability (\%) of HuH-7.5 cells upon treatment with compound D. (e) Dose-dependent inhibition (\%) of HCV replication by compound A in HuH-7.5 cells expressing S52/SG-Feo (SHI). (f) Dosedependent inhibition (\%) of HCV replication by compound D in HuH-7.5 cells expressing S52/SG-Feo (SHI). Bars represent the standard deviation of mean. Significant difference at $\mathrm{P}<0.05$. 
2002). Studies have shown that site-directed mutagenesis of amino acids in the catalytic triad promotes the abolishment of proteolytic cleavage at the four junctions, which are NS3/NS4A, NS4A/NS4B, NS4B/NS5A and NS5A/NS5B (Bartenschlager et al., 1993; Grakoui et al., 1993). This highlights the importance of the catalytic triad in the viral replication process. X-ray crystallography has revealed that the catalytic site possesses a shallow substrate binding groove (Kim et $a l ., 1996)$, foreseeing difficulty in uncovering suitable small molecule inhibitors (Lin, 2006). Virtual screening and redocking reveal that the 5 selected compounds are able to dock to the catalytic site groove and interact with its residues with compound A possessing excellent binding affinity similar to Simeprevir $(-7.8 \mathrm{Kcal} / \mathrm{mol})$.

Screening of compounds using Lipinski's rule of 5 and ADME/T properties was performed in order to obtain compounds with drug-like properties. There have been many prospective drug candidates that have proven ineffective in later stages of drug discovery and clinical studies due to unfavorable pharmacokinetic properties (Gombar et al., 2003; Wang \& Urban, 2004; Mandlik et al., 2015).

In spite of the numerous benefits associated with structure-based virtual screening, there are a few drawbacks that may arise such as false-positive results. Kim et al. (2018) suggested that these may occur as a result of conformational changes of the receptor through ligand binding and also via docking algorithm preferences in selecting true-positives, which may require evaluation on a case-by-case basis. One way to prevent false positives is to conduct in vitro experiments, as both docking and ADME/T predictions do not warrant efficiency of the compounds.

In vitro evaluation via protease and luciferase cell-based assay results in $\mathrm{IC}_{50}$ of $106.7 \mu \mathrm{M}$ and $\mathrm{EC}_{50}$ of $25.8 \mu \mathrm{M}$. Previous bioassay data on Simeprevir revealed that it is a very potent inhibitor of HCV, especially GT1. The median inhibition constant $\left(\mathrm{IC}_{50}\right)$ of Simeprevir against GT1a and GT1b is $0.5 \mathrm{nM}$ and $0.4 \mathrm{nM}$, respectively. In comparison, this is markedly reduced against GT3, $37 \mathrm{nM}$
(Lin et al., 2009; Tanwar et al., 2012). The $\mathrm{EC}_{50}$ of Simeprevir for GT1a and GT1b ranges between $8.1 \mathrm{nM}$ to $28.4 \mathrm{nM}$ (Lin et $a l ., 2009)$. However, the inhibition is reduced significantly by $\sim 1014$ folds in GT3 (Lenz et al., 2013).

Combining in silico and in vitro methods narrowed down compound A as a potential compound to be developed as an HCV GT3 NS3/4A serine protease inhibitor. Compound A is a chiral compound, docked as a single enantiomer and tested in vitro as an enantiopure compound. Analysis of its binding interactions with GT3 NS3/4A serine protease revealed that the compound is theoretically able to dock inside the shallow groove of the active site (Figure 2) with a binding conformation score of $8 / 9$. Compound $\mathrm{A}$ is predicted to inhibit catalysis by interacting with residues of the catalytic triad and those around the active site. The $2 \mathrm{D}$ diagram of the compound-protein interaction (Figure 2) illustrates that compound A forms hydrogen bonds with Ser139 through its phenyl group and oxazole and van der Waals interaction with His57. Ser139 is known to play key roles in NS3/4A serine protease catalysis, by attacking the carbonyl carbon of the substrate peptide's scissile bond assisted by His57 and Asp81 (Hedstrom, 2002; Raney et al., 2010). Compound A also interacts with two amino acids in the oxyanion hole; forming hydrogen bond with Gly137 through the oxazole and van der Waals interaction with Ser139. The oxyanion hole; Gly137 and Ser139 assist in stabilizing negative charges formed on the peptide carbonyl oxygen during the catalytic process making it one of the important residues in serine protease mechanism (Raney et al., 2010). Additionally, compound A interacts with four residues (Leu135, Phe154, Ala156, Ala157) located in the hydrophobic pockets of the active site. Similar patterns of interactions are formed from docking between Simeprevir to the NS3/4A serine protease of GT3; 4A1XB02 and from crystal structure of Simeprevir to the NS3/4A serine protease of GT1 (Cummings et al., 2010), through interactions with Ser139, His57 and Gly137, with more extensive interactions observed as it is a large macrocyclic compound (Supple- 
mentary Material; Figure S3). The loss of potency of Simeprevir towards GT3 compared to GT1 can be attributed to the loss of hydrogen bond interactions in the active site and the presence of active site polymorphism D168Q (Soumana et al., 2016). However, our analysis shows that binding of compound A appears to avoid any interactions with D168Q.

Thorough literature review of compound A has revealed only one previous bioassay data, as a modulator of the EP2 prostaglandin $\mathrm{E} 2$ receptor (NCBI, 2008). There are no reports on compound $\mathrm{A}$ against $\mathrm{HCV}$, especially the NS3/4A serine protease for GT3. The oxazole structure in compound A is interesting as it is able to form hydrogen bonds with two important residues; Ser139 and Gly137. Oxazole-based derivative compounds, aryloxazole and benzoxazole, have been used to develop inhibitors against HCV replication by targeting viral entry and NS5B polymerase, respectively (Ismail et al., 2013; He et al., 2017). There has also been development of many medicinal drugs that use oxazole and its derivatives such as antifungal (Wani et al., 2015), anti-bacterial (Prakash et al., 2014), anti-cancer (Choi et al., 2013), and anti-inflammatory (Pedada et al., 2016).

We acknowledge the limitations of our study, which includes (i) our virtual screening did not include any known NS3/4A mutants of HCV GT3, (ii) no structural modifications were performed on the current set of compounds, and (iii) the viral specificity of Compound A was not determined as no further testing was conducted on other HCV genotypes and human serine proteases. However, given that the development of antivirals specifically targeting GT3 NS3/4A is limited, we believe that there is a potential for additional structural optimizations of compound A to further improve its inhibition of HCV GT3 replication. It is also of interest to determine if compound A possesses the ability to inhibit replication of other HCV genotypes given the conserved nature of the NS3/4A serine protease catalytic triad (Naeem \& Waheed, 2017).

\section{CONCLUSION}

This study concludes compound $\mathrm{A}$ is a novel compound that has the potential to be developed as a small molecule inhibitor against the NS3/4A serine protease of HCV GT3 based on structure-based virtual screening methods in combination with protease and cell-based assays. Our data suggests that compound A inhibits viral replication via interactions with Ser139 and His57 in the catalytic site of the NS3/4A serine protease and Gly137 in the oxyanion hole. The low molecular weight and high bioavailability nature of this compounds makes it a favorable drug candidate. Modifications and structural changes may be able to increase its inhibitory potency. Overall, in silico screenings prior to biological investigations is a useful method for the rapid prediction, identification and selection of candidate compounds that can interact explicitly with the desired molecular target.

\section{Supplementary Materials}

All supplementary materials can be obtained from the corresponding author, upon request.

Acknowledgments. We thank Charles M. Rice (Rockefeller University, New York, USA) for the plasmid S52/SG-Feo (SHI) and Shamala Devi (University of Malaya, Kuala Lumpur, MY) for the Huh-7.5 cell line.

\section{Funding}

This project was supported by the Ministry of Education Malaysia-Transdisciplinary Research Grants Scheme (TR001B-2014B) and the University of Malaya Postgraduate Research Grant (PG238-2016A).

\section{Conflict of interest}

The authors report no conflicts of interest. 


\section{REFERENCES}

AASLD-IDSA HCV Guidance Panel (AASLDIDSA). (2018). Hepatitis C Guidance 2018 Update: AASLD-IDSA Recommendations for Testing, Managing, and Treating Hepatitis C Virus Infection. Clinical Infectious Diseases 67: 1477-1492.

Alland, C., Moreews, F., Boens, D., Carpentier, M., Chiusa, S., Lonquety, M., Renault, N., Wong, Y., Cantalloube, H., Chomilier, J., Hochez, J., Pothier, J., Villoutreix, B.O., Zagury, J.F. \& Tuffery, P. (2005). RPBS: a web resource for structural bioinformatics. Nucleic Acids Research 33(suppl_2): W44-49.

Bartenschlager, R. \& Lohmann, V. (2000). Replication of hepatitis C virus. Journal of General Virology 81(7): 1631-1648.

Bartenschlager, R., Ahlborn-Laake, L., Mous, J. \& Jacobsen H. (1993). Nonstructural protein 3 of the hepatitis $\mathrm{C}$ virus encodes a serine-type proteinase required for cleavage at the NS3/4 and NS4/5 junctions. Journal of Virology 67(7): 3835-3844.

Bassetto, M., Leyssen, P., Neyts, J., Yerukhimovich, M.M., Frick, D.N. \& Brancale, A. (2016). Computer-aided identification, synthesis and evaluation of substituted thienopyrimidines as novel inhibitors of HCV replication. European Journal of Medicinal Chemistry 123: 31-47.

Belema, M., Lopez, O.D., Bender, J.A., Romine, J.L., St. Laurent, D.R., Langley, D.R., Lem, J.A., O'Boyle, D.R., Sun, J., Wang, C., Fridel, R.A. \& Meanwell, N.A. (2014). Discovery and development of hepatitis $\mathrm{C}$ virus NS5A replication complex inhibitors. Journal of Medicinal Chemistry 57(5): 1643-1672.

Brenndörfer, E.D., Karthe, J., Frelin, L., Cebula, P., Erhardt, A., Schulte am Esch, J., Hengel, H., Bartenschlager, R., Sallberg, M., Haussinger, D. \& Bode, J.G. (2009). Nonstructural $3 / 4$ A protease of hepatitis $\mathrm{C}$ virus activates epithelial growth factor-induced signal transduction by cleavage of the Tcell protein tyrosine phosphatase. Hepatology 49(6): 18101820.
Carugo, O. \& Djinoviæ-Carugo, K. (2013). Half a century of Ramachandran plots. Acta Crystallographica Section D: Biological Crystallography 69(8): 1333-1341.

Chan, A., Patel, K. \& Naggie S. (2017). Genotype 3 Infection: The Last Stand of Hepatitis C Virus. Drugs 77(2): 131-144.

Chen, K.X. \& Njoroge, F.G. (2010). The journey to the discovery of boceprevir: an NS3NS4 HCV protease inhibitor for the treatment of chronic hepatitis C. In: Progress in medicinal chemistry, Lawton, G. \& Witty D.R. (editors) 1st edition. Amsterdam: Elsevier, pp. 1-36.

Choi, M.J., No, E.S., Thorat, D.A., Jang, J.W., Yang, H., Lee, J., Choo, H., Kim, S.J., Lee, C.S., Ko, S.Y., Lee, J., Nam, G. \& Pae, A.N. (2013). Synthesis and biological evaluation of aryloxazole derivatives as antimitotic and vascular-disrupting agents for cancer therapy. Journal of Medicinal Chemistry 56(22): 9008-9018.

Choo, Q.L., Kuo, G., Weiner, A.J., Overby, L.R., Bradley, D.W. \& Houghton, M. (1989). Isolation of a cDNA Clone Derived from a Blood-Borne Non-A, Non-B Viral Hepatitis Genome. Science 244(4902): 359-362.

Cummings, M.D., Lindberg, J., Lin, T.I., de Kock, H., Len, O., Lilja E., Fellander, S., Baraznenok, V., Nystrom, S., Nilsson, M., Vrang, L., Edlund, M., Rosenquist, A., Samuelsson, B., Raboisson, P. \& Simmen, K. (2010). Inducedfit binding of the macrocyclic noncovalent inhibitor TMC435 to its HCV NS3/NS4A protease target. Angewandte Chemie International Edition 49(9): 1652-1655.

Du, G.X., Hou, L.H., Guan, R.B., Tong, Y.G. \& Wang, H.T. (2002). Establishment of a simple assay in vitro for hepatitis $\mathrm{C}$ virus NS3 serine protease based on recombinant substrate and single-chain protease. World Journal of Gastroenterology 8(6): 1088.

Dustin, L.B. \& Rice, C.M. (2007). Flying under the radar: the immunobiology of hepatitis C. Annual Review of Immunology 25: 71-99. 
El Kassas, M., Elbaz, T., Hafez, E., Wifi, M.N. \& Esmat, G. (2017). Discovery and preclinical development of dasabuvir for the treatment of hepatitis $\mathrm{C}$ infection. Expert Opinion on Drug Discovery 12(6): 635-642.

Foster, G.R., Afdhal, N., Roberts, S.K., Bräu, N., Gane, E.J., Pianko, S., Lawitz, E., Thompson, A., Shiffman, M.L., Cooper, C., Towner, W.J., Conway, B., Ruane, P., Bouliere, M., Asselah, T., Berg, T., Zeuzem, S., Rosenberg, W., Agarwal, K., Stedman, C.A.M., Mo, H., Dvory, Sobol, H., Han, L., Wang, J., McNaly, J., Osinusi, A., Brainard, D.M., McHutchinson, J.G., Mazzotta, F., Tran, T.T., Gordon, S.C., Patel, K., Reau, N., Mangia, A. \& Sulkowski, M. (2015). Sofosbuvir and velpatasvir for HCV genotype 2 and 3 infection. New England Journal of Medicine 373(27): 2608-2617.

Ganesan, A. \& Barakat K. (2017). Applications of computer-aided approaches in the development of hepatitis C antiviral agents. Expert Opinion on Drug Discovery 12(4): 407-425.

Gombar, V.K., Silver, I.S. \& Zhao, Z. (2003), Role of ADME characteristics in drug discovery and their in silico evaluation: in silico screening of chemicals for their metabolic stability. Current Topics in Medicinal Chemistry 3(11): 1205-1225.

Grakoui, A., McCourt, D.W., Wychowski, C., Feinstone, S.M. \& Rice, C.M. (1993). Characterization of the hepatitis $\mathrm{C}$ virus-encoded serine proteinase: determination of proteinase-dependent polyprotein cleavage sites. Journal of Virology 67(5): 2832-2843.

Hajarizadeh, B., Grebely, J. \& Dore, G.J. (2013). Epidemiology and natural history of HCV infection. Nature Reviews Gastroenterology \& Hepatology 10(9): 553-562.

He, S., Li, K., Lin, B., Hu, Z., Xiao, J., Hu, X., Wang, A.Q., Xu, X., Ferrer, M., Southall, N., Zheng, W., Aube, J., Schoenen, F.J., Marugan, J.J., Liang, T.J. \& Frankowski, K.J. (2017). Development of an Aryloxazole Class of Hepatitis C Virus Inhibitors Targeting the Entry Stage of the Viral Replication Cycle. Journal of Medicinal Chemistry 60(14): 6364-6383.

Hedstrom, L. (2002). Serine protease mechanism and specificity. Chemical Reviews 102(12): 4501-4524.

Hwang, S.J. \& Lee, S.D. (2011). Hepatic steatosis and hepatitis C: still unhappy bedfellows? Journal of Gastroenterology and Hepatology 26: 96-101.

Irwin, J.J., Sterling, T., Mysinger, M.M., Bolstad, E.S. \& Coleman, R.G. (2012) ZINC: a free tool to discover chemistry for biology. Journal of Chemical Information and Modeling 52(7): 17571768.

Ismail, M.A.H., Adel, M., Ismail, N.S.M. \& Abouzid, K.A.M. (2013). Molecular Design, Synthesis and Cell Based HCV Replicon Assay of Novel Benzoxazole Derivatives. Drug Research 34(03): 109120.

Jacobson, I.M., Gordon, S.C., Kowdley, K.V., Yoshida, E.M., Rodriguez-Torres, M., Sulkowski, M.S., Shiffman, M.L., Lawitz, E., Everson, G., Bennet, M., Schiff, E., AlAssi, M.T., Subramaniam, M., An, D., Lin, M., McNally, J., Brainard, D., Symonds, W.T., McHutchinson, J.G., Patel, K., Feld, J., Pianko, S. \& Nelson, D.R. (2013). Sofosbuvir for hepatitis C genotype 2 or 3 in patients without treatment options. New England Journal of Medicine 368(20): 1867-1877.

Kanwal, F., Kramer, J.R., Ilyas, J., Duan, Z. \& ElSerag, H.B. (2014). HCV genotype 3 is associated with an increased risk of cirrhosis and hepatocellular cancer in a national sample of US Veterans with HCV. Hepatology 60(1): 98-105.

Kim, H.H., Hyun, J.S., Choi, J., Choi, K.E., Jee, J.G. \& Park S.J. (2018). Structural ensemble-based docking simulation and biophysical studies discovered new inhibitors of Hsp90 N-terminal domain. Scientific Reports 8(1): 1-13.

Kim, J.L., Morgenstern, K.A., Lin, C., Fox, T., Dwyer, M.D., Landro, J.A., Chambers, S.P., Markland, W., Lepre, C.A., O’Malley, E.T., Harbeson, S.L., Rice, C.M., Murcko, M.A., Carong, P.R. \& Thomson, J.A. (1996). Crystal structure of the hepatitis $\mathrm{C}$ virus NS3 protease domain complexed 
with a synthetic NS4A cofactor peptide. Cell 87(2): 343-355.

Kumar, A., Gupta, R., Verma, K., Iyer, K., Shanthi, V. \& Ramanathan, K. (2014). Identification of novel hepatitis $\mathrm{C}$ virus NS3-4A protease inhibitors by virtual screening approach. Journal of Microbial and Biochemical Technology 6(4): 1-7.

Kwong, A.D., Kauffman, R.S., Hurter, P. \& Mueller, P. (2011). Discovery and development of telaprevir: an NS3-4A protease inhibitor for treating genotype 1 chronic hepatitis C virus. Nature Biotechnology 29(11): 993.

Labbé, C.M., Rey, J., Lagorce, D., Vavruša, M., Becot, J., Sperandio, O. \& Miteva, M.A. (2015). MTiOpenScreen: a web server for structure-based virtual screening. Nucleic Acids Research 43(W1): W448W454.

Laskowski, R.A., MacArthur, M.W., Moss, D.S. \& Thornton, J.M. (1993). PROCHECK: a program to check the stereochemical quality of protein structures. Journal of Applied Crystallography 26(2): 283-291.

Lawitz, E., Mangia, A., Wyles, D., RodriguezTorres, M., Hassanein, T., Gordon, S.C., Schultz, M., Davis, M.N., Kayali, Z., Reddy, K.R., Jacobson, I.M., Kowdley, K.V., Nyberg, L., Subramanian, G.M., Hyland, G.H., Anterburn, S., Jiand, D., McNally, J., Brainard, D., Symonds, W.T., McHutchinson, J.G., Sheikh, A.M., Younossi, Z. \& Gane, E.J. (2013). Sofosbuvir for previously untreated chronic hepatitis C infection. New England Journal of Medicine 368(20): 1878-1887.

Lenz, O., Vijgen, L., Berke, J.M., Cummings, M.D., Fevery, B., Peeters, M., Smedt, G.D., Moreno, C. \& Picchio, G. (2013). Virologic response and characterisation of $\mathrm{HCV}$ genotype $2-6$ in patients receiving TMC435 monotherapy (study TMC435C202). Journal of Hepatology 58(3): 445-451.

Li, H., Leung, K.S. \& Wong, M.H. (2012). idock: A multithreaded virtual screening tool for flexible ligand docking. In: Computational Intelligence in Bioinformatics and Computational Biology
(CIBCB), 2012 IEEE Symposium, pp. 7784.

Li, J., Liu, X., Li, S., Wang, Y., Zhou, N., Luo, C., Luo, X., Zheng, M., Jiang, H. \& Chen, K. (2013). Identification of novel small molecules as inhibitors of hepatitis $\mathrm{C}$ virus by structure-based virtual screening. International Journal of Molecular Sciences 14(11): 22845-22856.

Lin, C. (2006). HCV NS3-4A serine protease. In: Hepatitis $\mathrm{C}$ viruses: Genomes and Molecular Biology, Tan S.L. (editor). Norfolk: Horizon Bioscience, pp. 163-206.

Lin, T.I., Lenz, O., Fanning, G., Verbinnen, T., Delouvroy, F., Scholliers, A., Vermeiren, K., Rosenquist, A., Edlund, M., Samuelsson, B., Vrang, L., de Kock, H., Wigerinck, P., Roboisson, P. \& Simmen, K. (2009). In vitro activity and preclinical profile of TMC435350, a potent hepatitis $\mathrm{C}$ virus protease inhibitor. Antimicrobial Agents and Chemotherapy 53(4): 1377-1385.

Lipinski, C.A., Lombardo, F., Dominy, B.W. \& Feeney, P.J. (2001). Experimental and computational approaches to estimate solubility and permeability in drug discovery and development settings. Advance Drug Delivery Reviews 46: 326.

Lipinski, C.A., Lombardo, F., Dominy, B.W. \& Feeney, P.J. (1997). Experimental and computational approaches to estimate solubility and permeability in drug discovery and development settings. Advance Drug Delivery Reviews 23(13): 3-25.

Lontok, E., Harrington, P., Howe, A., Kieffer, T., Lennerstrand, J., Lenz, O., McPhee, F. Mo, H., Parkin, N., Pilot-Matias, T. \& Miller, V. (2015). Hepatitis C virus drug resistance-associated substitutions: State of the art summary. Hepatology 62(5): 1623-1632.

Love, R.A., Parge, H.E., Wickersham, J.A., Hostomsky, Z., Habuka, N., Moomaw, E.W., Adachi, T. \& Hostomska, Z. (1996). The crystal structure of hepatitis C virus NS3 proteinase reveals a trypsin-like fold and a structural zinc binding site. Cell 87(2): 331-342. 
Lüthy, R., Bowie, J.U. \& Eisenberg, D. (1992). Assessment of protein models with three-dimensional profiles. Nature 356(6364): 83-85.

Mandlik, V., Bejugam, P.R. \& Singh, S. (2015). Application of Artificial Neural Networks in Modern Drug Discovery. In: Artificial Neural Network for Drug Design, Delivery and Disposition, Puri, M., Pathak, Y., Sutariya, V.J., Tipparaju, S. \& Moreno, W. (editors). London: Academic Press, pp. 123-139.

Naeem, A. \& Waheed, Y. (2017). Sequence analysis of hepatitis $\mathrm{C}$ virus nonstructural protein $34 \mathrm{~A}$ serine protease and prediction of conserved $\mathrm{B}$ and $\mathrm{T}$ cell epitopes. Biomedical Reports 7(6): 563-566.

National Center for Biotechnology Information (NCBI). PubChem BioAssay Database; AID=940. (2008) Retrieved from https://pubchem.ncbi.nlm.nih.gov/ bioassay $/ 940$

Néron, B., Ménager, H., Maufrais, C., Joly, N., Maupetit, J., Letort, S., Carrere, S., Tuffery, P. \& Letondal, C. (2009). Mobyle: a new full web bioinformatics framework. Bioinformatics 25(22): 3005-3011.

Ng, T.I., Tripathi, R., Reisch, T., Lu, L., Middleton, T., Hopkins, T.A., Pithawalla, R., Irvin, M., Dekhtyar, T., Krishnan, P., Schnell, G., Beyer, J., McDaniel, K.F., Ma, J., Wang, G., Jiang, L., Or, Y.S., Kemp, D., Pilot-Matias, T. \& Collins, C. (2018). In vitro antiviral activity and resistance profile of the next-generation hepatitis $\mathrm{C}$ virus NS3/4A protease inhibitor glecaprevir. Antimicrobial Agents and Chemotherapy 62(1): e01620-17.

Pawlotsky, J.M., Negro, F., Aghemo, A., Berenguer, M., Dalgard, O., Dusheiko, G., Marra, F., Puoti, M. \& Wedemeyer, H. (2018). EASL Recommendations on Treatment of Hepatitis C 2018. Journal of Hepatology 69(2): 461-551.

Pal, D. \& Chakrabarti, P. (2002). On residues in the disallowed region of the Ramachandran map. Biopolymers: Original Research on Biomolecules 63(3): 195-206.
Pedada, S.R., Yarla, N.S., Tambade, P.J. Dhananjaya, B.L., Bishayee, A., Arunasree, K.M., Philip, G.H., Dharmapuri, G., Aliev, G., Putta, S. \& Rangaiah, G. (2016). Synthesis of new secretory phospholipase A2-inhibitory indole containing isoxazole derivatives as anti-inflammatory and anticancer agents. European Journal of Medicinal Chemistry 112: 289-297.

Petruzziello, A., Marigliano, S., Loquercio, G., Cozzolino, A. \& Cacciapuoti, C. (2016). Global epidemiology of hepatitis C virus infection: An update of the distribution and circulation of hepatitis $\mathrm{C}$ virus genotypes. World Journal of Gastroenterology 22(34): 7824-7840.

Pinzani, M., Rombouts, K. \& Colagrande, S. (2005). Fibrosis in chronic liver diseases: diagnosis and management. Journal of Hepatology 42(1): S22-S36.

Poveda, E., Wyles, D.L., Mena, Á., Pedreira, J.D., Castro-Iglesias, Á. \& Cachay, E. (2014). Update on hepatitis C virus resistance to direct-acting antiviral agents. Antiviral Research 108: 181-191.

Prakash, T.B., Reddy, G.D., Padmaja, A. \& Padmavathi, V. (2014). Synthesis and antimicrobial activity of amine linked bis-and tris-heterocycles. European Journal of Medicinal Chemistry 82: 347-354.

Raj, V.S., Hundie, G.B., Schürch, A.C., Smits, S.L., Pas, S.D., Pogam, S., Janssen, H.L.A., de Knegt, R.J., Osterhaus, A.D.M.E., Najera, I., Boucher, C.A. \& Haagmans, B.L. (2017). Identification of HCV resistant variants against direct acting antivirals in plasma and liver of treatment naïve patients. Scientific Reports 7(1): 1-10.

Raney, K.D., Sharma, S.D., Moustafa, I.M. \& Cameron, C.E. (2010). Hepatitis C virus non-structural protein 3 (HCV NS3): a multifunctional antiviral target. Journal of Biological Chemistry 285(30): 2272522731.

Roingeard, P. (2013). Hepatitis C virus diversity and hepatic steatosis. Journal of Viral Hepatitis 20(2): 77-84. 
Rosenquist, Å., Samuelsson, B., Johansson, P.O., Cummings, M.D., Lenz, O., Raboisson, P., Simmen, K., Vendeville, S., de Kock, H., Nilsson, M., Horvath, A., Kalmeijer, R., de la Rosa, G. \& BeumontMauviel, M. (2014). Discovery and development of simeprevir (TMC435), a HCV NS3/4A protease inhibitor. Journal of Medicinal Chemistry 57(5): 1673-1693.

Saeed, M., Scheel, T.K., Gottwein, J.M., Marukian, S., Dustin, L.B., Bukh, J. \& Rice, C.M. (2012). Efficient replication of genotype $3 \mathrm{a}$ and $4 \mathrm{a} \mathrm{HCV}$ replicons in human hepatoma cells. Antimicrobial Agents and Chemotherapy 56(10): 53655373.

Simmonds, P., Becher, P., Bukh, J., Gould, E.A., Meyers, G., Monath, T., Muerhoff, S., Pletnev, A., Rico-Hesse, R., Smith, D.B. \& Stapleton, J.T. (2017). ICTV Virus Taxonomy Profile: Flaviviridae. Journal of General Virology 98(1): 2-3.

Smith, D.B., Bukh, J., Kuiken, C., Muerhof, A.S., Rice, C.M., Stapleton, J.T. \& Simmonds, P. (2019). HCV classification: A web resource to manage the classification and genotype and subtype assignments of hepatitis C virus. In Flaviviridae Study Group. Retrieved from https:// talk.ictvonline.org/ictv_wikis/ flaviviridae/w/sg_flavi/56/hcvclassification

Sofia, M.J. (2016). Sofosbuvir: The Discovery of a Curative Therapy for the Treatment of Hepatitis C Virus. Successful Drug Discovery 2: 163-188.

Soumana, D.I., Yilmaz, N.K., Ali, A., Prachanronarong, K.L. \& Schiffer, C.A. (2016). Molecular and dynamic mechanism underlying drug resistance in genotype 3 hepatitis C NS3/4A protease. Journal of the American Chemical Society 138(36): 11850-11859.

Tanwar, S., Trembling, P.M. \& Dusheiko, G.M. (2012). TMC435 for the treatment of chronic hepatitis C. Expert Opinion on Investigational Drugs 21(8): 1193-1209.
Trott, O. \& Olson, A.J. (2010). AutoDock Vina: improving the speed and accuracy of docking with a new scoring function, efficient optimization, and multithreading. Journal of Computational Chemistry 31(2): 455-461.

Vermehren, J. \& Sarrazin, C. (2012). The role of resistance in HCV treatment. Best Practice \& Research Clinical Gastroenterology 26(4): 487-503.

Wang, J. \& Urban, L. (2004). The impact of early ADME profiling on drug discovery and development strategy. Drug Discovery World 5(4): 73-86.

Wani, M.Y., Ahmad, A., Shiekh, R.A., AlGhamdi, K.J. \& Sobral, A.J. (2015). Imidazole clubbed 1, 3, 4-oxadiazole derivatives as potential antifungal agents. Bioorganic \& Medicinal Chemistry 23(15): 4172-4180.

World Health Organization (WHO). Hepatitis C (2017). Retrieved from http://www. who.int/news-room/fact-sheets/detail/ hepatitis-c

Wyles, D., Poordad, F., Wang, S., Alric, L., Felizarta, F., Kwo, P.Y., Maliakkal, B., Agarwal, K., Hassanein, T., Weilert, F., Lee, S.S., Kort, J., Lovell, S.S., Liu, R., Lin, C., Pilot-Matias, T., Krishnan, P. \& Mensa, F.J. (2018). Glecaprevir/pibrentasvir for hepatitis $\mathrm{C}$ virus genotype 3 patients with cirrhosis and/or prior treatment experience: a partially randomized Phase 3 clinical trial. Hepatology 67(2): 514-523.

Yu, W., Tong, L., Selyutin, O., Chen, L., Hu, B., Zhong, B., Hao, J., Ji, T., Zan, S., Yin, J., Ruck, R.T., Curry, S., McMonagle, P., Agrawal, S., Rokosz, L., Carr, D. Ingravallo, P., Bystol, K., Lahse, F., Liu, R., Chen, S., Feng, K., Cartwright, M., Asante-Appiah, E. \& Kozlowski, J.A. (2018). Discovery of MK-6169, a Potent Pan-Genotype Hepatitis C Virus NS5A Inhibitor with Optimized Activity against Common Resistance-Associated Substitutions. Journal of Medicinal Chemistry 61(9): 3984-4003. 